\title{
ENTREPRENEURIAL ENERGY IN A FAR-FROM-EQUILIBRIUM OPPORTUNITY DRIVING ENTREPRENEURIAL ACTIONS
}

\author{
David Leong \\ University of Canberra, Bruce ACT 2617, Australia \\ E-mail: u3221961@uni.canberra.edu.au \\ Received October 2020; accepted January 2021
}

\begin{abstract}
Disequilibrium and complexity are the distinguishing characteristics of entrepreneurial phenomena. How do the entrepreneurs arbitrage, leverage and benefit in the disequilibria and what spur them to action? The force that drives entrepreneurial ventures, from creation to sustaining through to exit, and then through innovation to extend the game or recreate another play is an imminent force that holds and sustains entrepreneurial momentum. Entrepreneurial energy, a coined terminology in this paper, is that endogenous force. There are scarce relevant researches. In particular, there is no specific mention of the "entrepreneurial energy" in the theory of entrepreneurship. The closest proxy is entrepreneurial passions. Passion cannot be held in equal doses throughout the venture pathway. John Maynard Keynes coined the phrase "animal spirits" in his 1936 book "The General Theory of Employment, Interest and Money". He used the term to describe emotions that influence human economic behaviour. Animal spirits create an ambience of trust and faith and are necessary for human actions, more than quantitative logic. Keynes felt animal spirits were needed as a goad to economic action rather than inaction. Schumpeter came up with the German word Unternehmergeist, meaning entrepreneur-spirit, adding that these individuals controlled the economy because they are responsible for delivering innovation and technological change. Whether its entrepreneurial energy, animal spirit or entrepreneur-spirit, it is a force that needs reckoning with in entrepreneurship study. Entrepreneurship is a science of turbulence and change, not continuity. A certain force causes turbulence. Such is the force in entrepreneurship like the wind is felt but not seen through the leaves' ruffle but not the wind itself. This paper will demonstrate that entrepreneurial energy can be better understood if examined through the lens of complexity and quantum science to address this omission. The indeterminacy in uncertainties and chaos theories best describe the dynamically complex, fast, volatile, uncertain disrupted, diverse, ambiguous, hyper-turbulent and hyperconnected entrepreneurial ecosystem. This paper contributes to entrepreneurship research by developing a complexity-based and uncertainty-based definition of entrepreneurial energy. This energy will be referred to in the context of the entrepreneurial ecosystem (space) where the entrepreneurs (object) exist over time. Building on this definition, it connects the research on the entrepreneur to venturelevel complexity and entrepreneurial multi-finalities/pathways. It explores how these force originates and is sustained- that will influence entrepreneurial emergence and continuation- from the intentionality of entrepreneurs and the coherence of entrepreneurial activities, through the exploration and exploitation of perceived opportunities within the entrepreneurial ecosystem. Beyond theory development, it explores how scholars can examine entrepreneurial energy as a complex play of forces through interpretivist methods. This paper has implications for entrepreneurs and policymakers.
\end{abstract}

\section{Research paper}

Keywords: Entrepreneurship; Complexity science; Far-from-equilibrium; Structuration theory

Reference to this paper should be made as follows: Leong, D. (2021). Entrepreneurial Energy in a FarFrom-Equilibrium Opportunity Driving Entrepreneurial Actions. Journal of Entrepreneurship, Business and Economics, 9(1), 1-31. 
Leong, D. 2021. Entrepreneurial Energy in a Far-From-Equilibrium Opportunity Driving Entrepreneurial Actions

\section{Complexities of Entrepreneurship}

The complexities of the entrepreneurship and entrepreneurial process can be observed from various paradigms and philosophical lenses depending on the exploration mood and angle. Diagram 1, adopted from (Johnson \& Duberley, 2000), illustrates the codification of entrepreneurship under various observations with the varied paradigms.

Entrepreneurship has been defined as the nexus of the entrepreneur and opportunities (Sarason et al., 2006; Davidsson, 2015). This nexus exists in the entrepreneurial ecosystem. Entrepreneurship can be observed from a multi-paradigm approach.

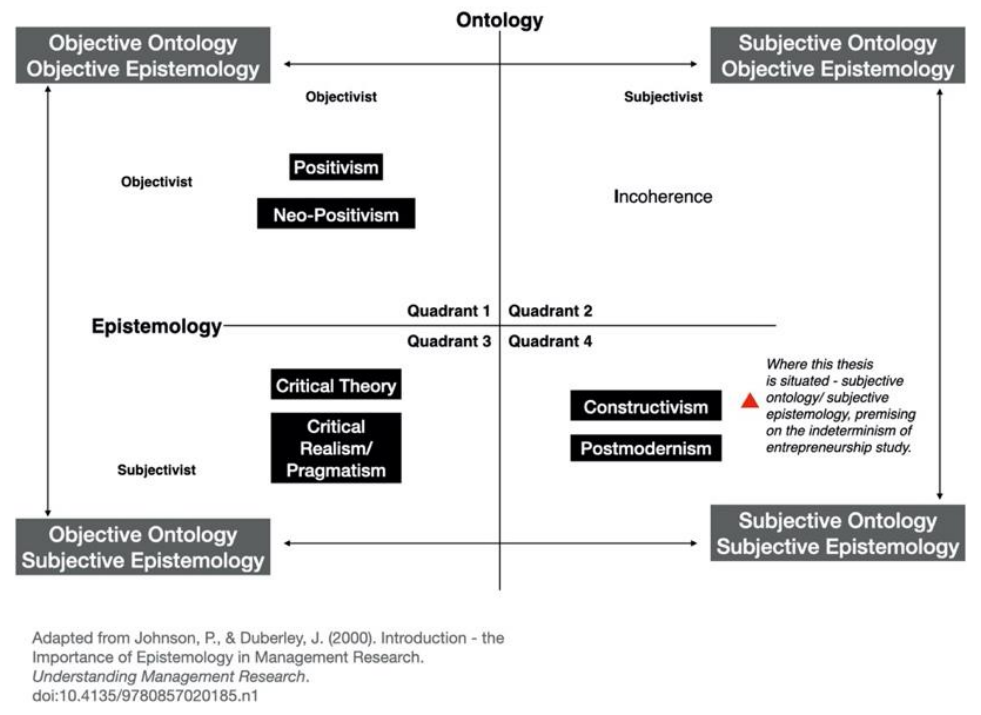

Diagram 1. Ontological/Epistemological positioning (Source: Johnson \& Duberley, 2000) 
Whither the promise of entrepreneurship? (Venkataraman et al., 2012) The promise of entrepreneurship lies in the nexus of the entrepreneur and opportunities (Shane \& Venkataraman, 2000). The nature of entrepreneurial opportunities is deeply social as well as institutional (Venkataraman et al., 2012). The study of the nature of the nexus, ontologically and epistemologically for entrepreneurial research is necessary to give clarity (Sarason et al., 2006; Sarason et al., 2010). Entrepreneurial studies need solid dredging into the foundations and nature of opportunities (Alvarez \& Barney, 2007); (Ramoglou, 2013); (Randerson et al., 2016). This paper is discussed with the anchor in Quadrant 4, shown in Diagram 1, basing on subjective ontology/ subjective epistemology. This paper will be featuring entrepreneurial energy arising in the space of risks and opportunities. In complexity science, there are two distinct drivers of emergence, one which is the far-from-equilibrium dynamics that trigger order creation and the second, adaptive tension that can push a system towards instability (Lichtenstein, 2007). Lichtenstein re-defined the adaptive tension and suggested "opportunity tension" which captures the entrepreneurial passion inherent in the drive for order creation and emergence (Lichtenstein, 2007).

In this constructivist pivot, it involves understanding how the entrepreneurs as human agents make sense of equivocal inputs and enact this sense back into the world to make it more orderly (Weick \& Karl, 1995) with an understandable pattern and structure through stereotyping or through noticing and bracketing, both retrospectively and prospectively (Weick et al., 2005). 
In short, seeing orderliness amidst chaos or the move towards chaos in Prigogine's dissipative structures (Prigogine \& Lefever, 1968; Goldstein, 2013).

In McKelvey's (Mckelvey, 2002) understanding of Prigogine's dissipative structures theory, order creation arises from "energy differentials" which are imposed onto the system. (McKelvey, 2004) "A more recent view is that the most significant dynamics in bio- and econospheres are not variances around equilibria. Instead, order is now seen to be due to the interactions of autonomous, heterogeneous agents energized by contextually imposed tensions induced by energy differentials." Plowman (Plowman et al., 2007) further elaborated and suggested: “...the tug and pull of these counteracting forces may push the organization away from equilibrium into a more chaotic state....described this region of complexity as full of adaptive tension and tension gradients; it is in this state that emergent self-organization and creative destruction occur. An organization approaches a far-from-equilibrium state when members have enough freedom to experiment with new ways of doing things that their discoveries lead to disorder capable of moving through the entire organization. " In these described models, adaptive tension is effected from the energy differential that initiates a dynamic state that leads to emergence and order creation. In sum, we have a bit of a conflict around causality: What actually causes the emergence of new order? Summarily, McKelvey mentioned the dynamism and the variance around equilibria. What causes the dynamism and variance around equilibria? Plowman mentioned "the tug and pull of these counteracting force" and "tension gradient" and what is this force and what move between the "tension gradient"? 
In the far-from-equilibrium approach, the entire system moves into a regime that is away from equilibrium; this "far-from-equilibrium" organizing leads to non-linearities, adaptive tensions, and ultimately to perturbations of novelty (Lichtenstein, 2007). Under continuing far-from-equilibrium conditions, a new order will emerge. What causes the perturbations and wobbling effect away from equilibrium. In this paper, entrepreneurial energy is the force that causes the tension gradient and causing the perturbations and wobbling effect resulting in the variance around equilibria.

A focus on understanding the nexus through the constructivist lens has been offered by (Cornelissen \& Clarke, 2010) who describe the nexus in entrepreneurship as an exercise in sensemaking, emphasizing a direct relationship among language, cognition, and enactment of entrepreneurs. The nexus provides that space for the creation and commercialization of novel ventures by constructing meaning for themselves and others. It also drew upon sensemaking in understanding the nexus by offering a narrative perspective on the entrepreneurial opportunity (Alvarez \& Barney, 2013). They argue that the emphasis in this perspective is what emerges through actions and interactions of the entrepreneurs. It is in this nexus that entrepreneurial energy arises and lead to actions. 


\section{On Entrepreneurial Energy}

This paper intends to define entrepreneurial energy as the force that spurs the dynamic entrepreneurs to action across the entrepreneurial venture stages from founding to exit (Leong, 2020). The research question being addressed in this paper is how entrepreneurial energy plays a role in venture emergence, creation and sustenance process, and if so, how does entrepreneurial energy influences venture development along the venture pathway?

Entrepreneurial energy is an endogenous force that fuels motivation and sustains entrepreneurial action and momentum. Encapsulating hope, optimism, and obsessiveness, the entrepreneurial energy's nature and experience provide meaning to the entrepreneurial pursuit and venture. Entrepreneurial energy is a motivational construct characterised by intense positive feeling, emotional arousal and internal drive and engagement in the pursuit that is salient to the entrepreneur's self-identification. The positive affective state also generates positivity in the cognitive state fostering creativity and recognising new patterns of information critical to opportunity recognition and exploitation in the external environment. Entrepreneurial energy is the force that sustains the momentum and velocity of progression in the venture. Energy can rise through excitation/ agitation and fall through the energy decay due to predicaments or failures.

Entrepreneurial energy leads to an acute alertness to market opportunities and the human agent's (entrepreneur's) actions to capture the opportunities. See Diagram 2. Likewise, when the entrepreneurial energy decays due 
to demotivation and failures, the entrepreneur's energy curve dips. Entrepreneurial energy's dynamism is indeterministic, and it has a wave function. The fluctuation of the wave across the timeline shows the entrepreneurs' trial-anderror processual pathway for survival, with peaks and troughs in energy level. Any decisions, moving along the processual pathway is ex-ante, with no perfect knowledge and rationality, and whatever potential economic outcome, the decisions are experimentally determined with different creative combinations. With success, the entrepreneurs' energy becomes elevated and is charged up; similarly, demotivation and depression will cause the dip in the energy with failures or obstacles.

What is the difference between energy that spurs human agent to action and entrepreneurial energy? Entrepreneurial energy heightens the state of motion and subsequent actions for entrepreneurs to assume the risk associated with uncertainty (Knight, F, 1921) for eventual wealth creation. The ultimate source of profits then is the foresight of future conditions and wants. (Mises, 1949). Entrepreneurs overarching goal is wealth creation.

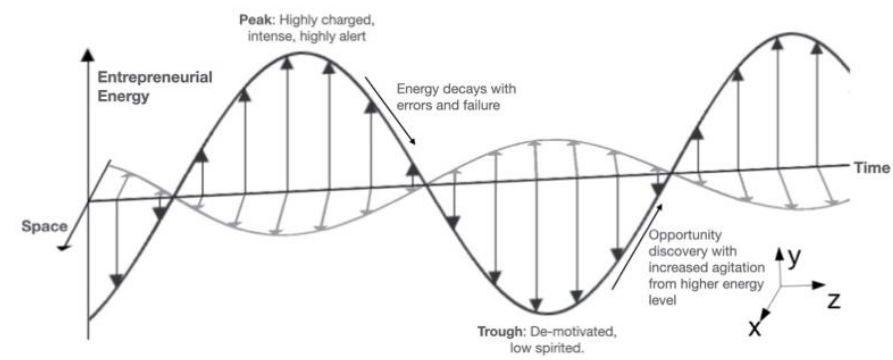

Diagram 2. Entrepreneurial energy "peak-and-valley" cycle (source: author's elaboration) 
The research will primarily try to uncover the determinants of entrepreneurial energy and the effects of entrepreneurial energy on cognitions, passions and behavioural outcomes and how it creates the different pathways arising from decisions and strategies.

The entrepreneurial process is a dynamic, discontinuous change of the state of entrepreneurial energy that will drive human action. Human action the ends aimed at and the means chosen - is determined by every individual human agent's qualities. Every human agent uses understanding in dealing with uncertain future events, but is motivated by an energy to persist despite the uncertainties, to which the entrepreneur must routinely adjust and calibrate actions. Aimed to address such uncertainty, action is always speculative and contingent on the level of energy that will spur actions into the various possible venture pathways. The end or aim of any action is always the relief from a felt uneasiness. A means is what serves the attainment of any end. According to Mises, "In this universe there exist only things." A thing becomes a means when human reason plans to employ it for attainment of some end. Economics is not about things and tangible material objects; it is about individuals, their meanings and actions. (Mises, 1949). Hence, it is clear from Mises that active human agent who is the economic actor, in this case the entrepreneur. In this paper, it will be argued with proof of cases from researches and literatures how is human action, defined as energised human action drives outcome of success and failures or how energy drives innovativeness to other pathway or to creatively destruct the original pathway to 
create a new one. Consequently, the entrepreneur is a disturber of equilibrium and causes creative destruction (Schumpeter, 1942) through this same energy.

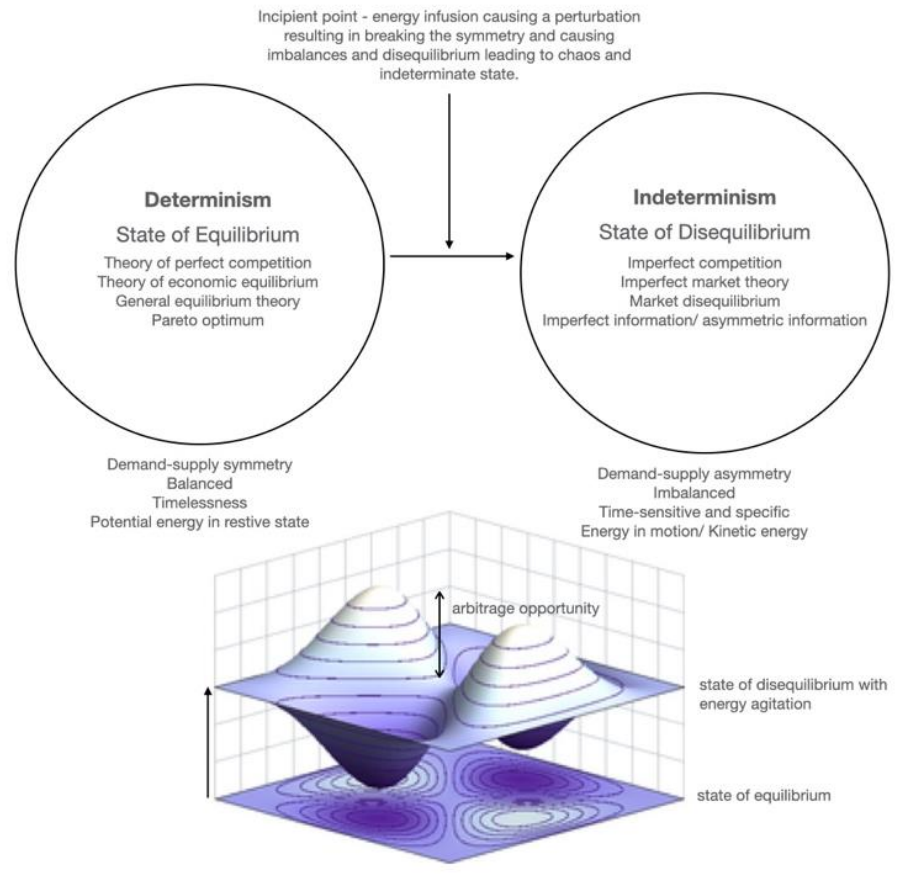

Diagram 3. From the state of equilibrium to the state of disequilibrium producing arbitrage opportunity (source: author's elaboration)

\section{The Model}

Researches on entrepreneurship have always been a controversial topic in economic theorization. The significance of entrepreneurship premising on various themes from entrepreneurial orientation, entrepreneurial pas- 
sion, effectuation theory, structuration theory or decision theory/schema theory, among the many strands of thoughts, provide only limited perspective. Most of the research lacks a unifying explanation of what continues to affect and affects the human agent's (entrepreneur's) actions and activities along the venture pathway. A consistent theory of entrepreneurship is missing; a theory that is adequate to combine the various strands of themes, including from determinism to indeterminism, in order to come to a model that can consistently link all these themes eventually. Early theories approach entrepreneurship from a intuitive perspective, tracing back to Cantillon (1931) and Schumpeter (1934), to eventually contemplating a modern evolutionary approach based on indeterminism (Diagram 4 showing the determinism and indeterminism correlation to physics, biology, economics and philosophy) containing some specific theories such as the Heisenberg theory (Soros, 2013) and Feynman's diagram on quantum field theory to explain the chaotic dynamics (Cvitanovi, 2000) in the natural entrepreneurial ecosystem. Walrus's general equilibrium theory is a case in point of determinism (Walras, 1874). Walras's law is an economic theory, which states that the existence of excess supply in one market must be matched by excess demand in another market so that both factors are balanced out. Walras's law asserts that an examined market must be in equilibrium if all other markets are in equilibrium. Equilibrium needs optimal behaviour. Optimal behaviour needs perfect rationality. Perfect rationality requires perfect foresight and information. This is not at all congruent with reality which is not in a state of perfect equilibrium with perfect rationality and 
thereafter perfect behaviour. Perfect knowledge, perfect rationality and perfect behaviour in a state of total equilibrium is therefore unreal if the measurement of time is involved. The bone of contention is rooted in the perfect rationality assumption, which is a necessary condition for optimal behaviour. This does not allow for a 'real' choice and the treatment of true uncertainty subject to entrepreneurial behaviour, which burns down the entrepreneur's role to a static and passive and therefore redundant economic agent. Any model built on perfect foresight and rationality with complete information is a contradiction in itself. Until an appropriate methodology that can accommodate this indeterminism and re-interpret the equilibrium concept to provide for the morphing from determinism to indeterminism, new theorizations need to address the realities faced by entrepreneurs who are alternating between equilibrium-destruction (innovating) (Chiles et al., 2007) and equilibriumseeking (Valliere, 2013). 
Leong, D. 2021. Entrepreneurial Energy in a Far-From-Equilibrium Opportunity Driving Entrepreneurial Actions

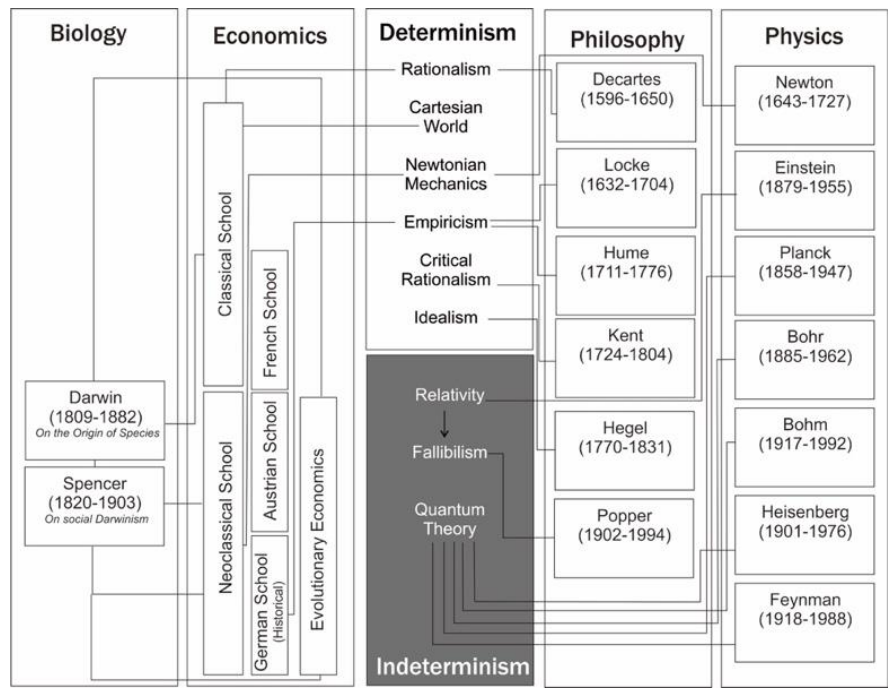

Diagram 4. Adapted from Grebel, T. (2007). Entrepreneurship: A New Perspective (source: author's elaboration)

\section{Human Actions}

The core element of in the model are the actors who are the dynamic entrepreneurs driven by purposeful, energized human action. These actors exist in an ecosystem of risks and opportunities, and there is a certain regularity and interdependence of market phenomena which is built upon the solid foundation of the general theory of human action, or praxeology. Proxeology is the theory of human action based on the notion that humans engage in purposeful behaviour as opposed to reflexive or unintentional behaviours. French social philosopher Alfred Espinas (Espinas, 1897) gave the term its modern meaning. Modern economics calls praxeology the science of choice and it studies choices that inevitably flow from scarcity. In contemporary neoclassical theory, human agents are modelled and fashioned as rational agents that 
maximize utility subject to constraints. In the most simplified form, the human agent's specific action is a point in space "M" (See Diagram 5). Mises (1949) began from a different concept of choice and subsequently weaved a dramatically different foundation for economic theory.

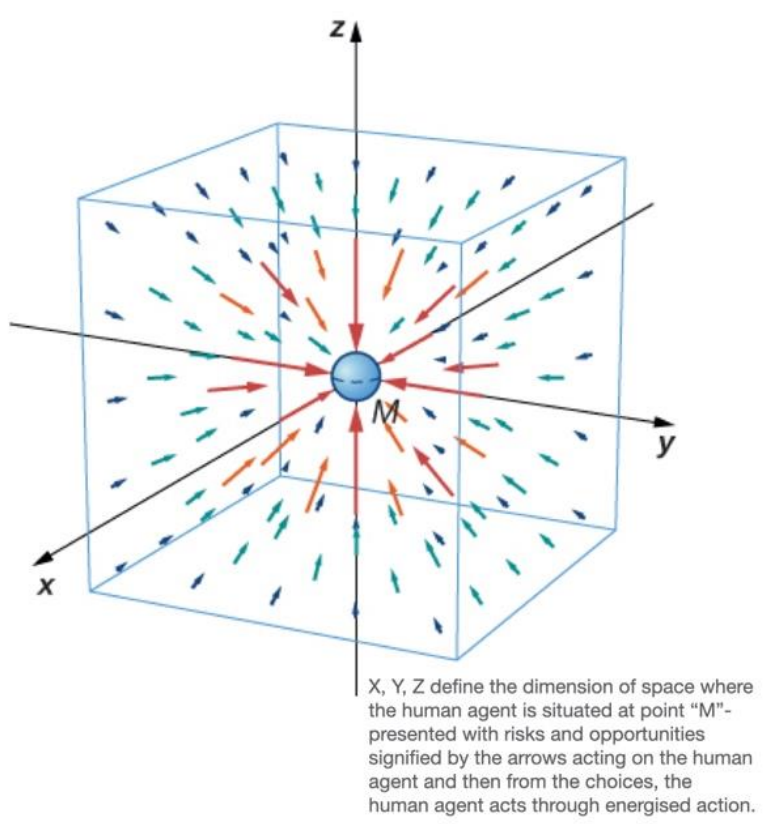

Diagram 5. Entrepreneur's spatiotemporal position and interacting with risks and opportunities in space (Source: author's elaboration)

Without considering causality and regularity of phenomena, there will be no field for human reasoning and subsequent action that will lead to the many venture pathways. The specific study of human action is always com- 
plex, thus rendering the notion of scientific positivism impossible. Praxeology, will be used as a lens in this paper to understand how entrepreneurial energy and perception of risk in entrepreneurs' choice of strategies adoption affect subsequent action. This is part of the research question in the paper.

The model set up in this paper involves the study of means and uncertainties over time. Means, time and uncertainties are important considerations though it is mentioned at the beginning that the core of the study is on human action. How from the choices of means, adoption of strategies for capturing opportunities through strategies, to specific action that would lead to an outcome. If means were not scarce, there would not be any action with regard to them. Again the principle of scarcity applies. Action is an attempt to substitute a more satisfactory state of affairs for a less satisfactory one. The variance between the value of the costs incurred and that of the outcome attained is called a gain or loss. Profit and loss are purely subjective depending on the time of measure- any calculation of values is impossible unless there is a terminal end to compute all the gains and losses. Momentary loss or gain cannot be the same final loss or gain because it is still in the process of adding up and being averaged out. Thus, human action must take into account time in attaining a certain end. Time is scarce. Human agent must economize time as another scarce factor. The intention of all means serves toward an optimum utility over time. Mises discussed the relation of labour as a means: "The employment of the physiological functions and manifestations of human life as a means is called labour." In this paper, the human agent refers to entrepre- 
neur, works only when the return of labour is deemed higher than the satisfaction brought about by leisure. Labour is also a scarce mean of production. Mises (1949) stated that the use of "means" "is a transformation of given elements through arrangement and combination. It is the method that man, directed by reason, employs for the best possible removal... of his own unease." Owing to the high degree of free-will to entrepreneurial behaviour, true uncertainty follows. Entrepreneurs neither know the set of possible outcomes nor the corresponding probabilities. Entrepreneurs have to make decisions to the best to their knowledge, to craft out a venture pathway to proceed through Mises's human actions (Mises, 1949), arising from entrepreneurial energy. Entrepreneurs have to evaluate their individual endowment of resources, capabilities, capacities and competencies and second, the chances or possibilities to acquire missing complementarities through borrowing resources and third, to effectively assess the economical situation as shown in Diagram 3 where the risks and opportunities are surrounding the actor/ entrepreneur at position " $\mathrm{M}$ " at a particular point in time. In this case where the entrepreneur's perceived endowments, environmental suitability (basing on the perception of risks and opportunities) appear to be sufficient to enter a market, through energized human action, with the expected conclusion of a future that signals promising rewards, a new pathway is being crafted out. 
Leong, D. 2021. Entrepreneurial Energy in a Far-From-Equilibrium Opportunity Driving Entrepreneurial Actions

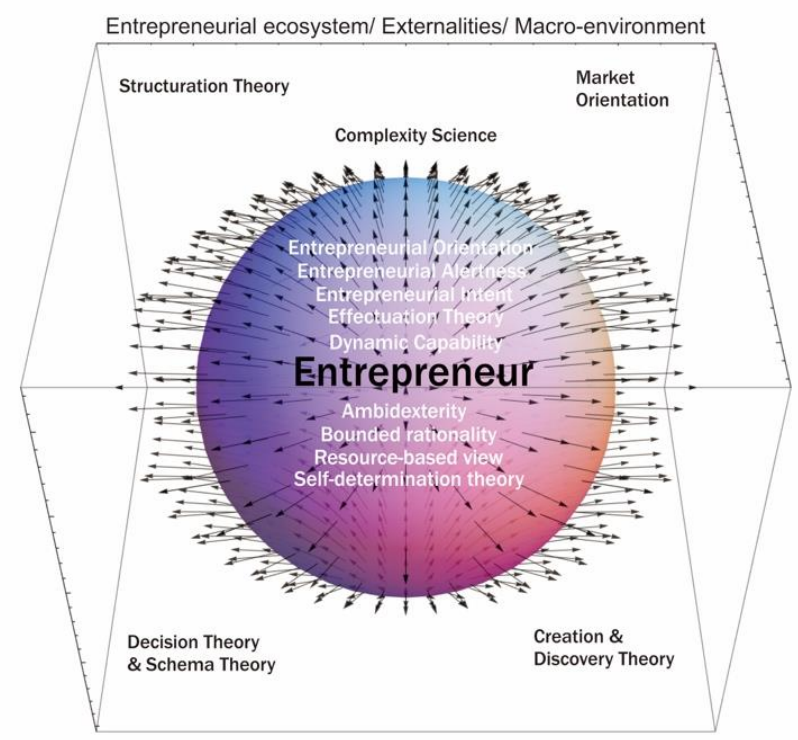

Diagram 6. Entrepreneur in an entrepreneurial ecosystem (source: author's elaboration)

\section{Space Context}

In theorizing about entrepreneurship in this paper, the concept of space is crucial because entrepreneurial action do not exist independent of space or time but in a specific space-time (See, Diagram 6). Therefore, the study will feature research on individual and venture-level entrepreneurial emergence and the role of orientation/ intention and action in creating new ventures. The space in which the study will premise will be called the entrepreneurial ecosystem. This paper will study the three related forces that work in tandem to influence the emergence of the ecosystem: the orientation/ in- 
tentionality and adaptive tensions of entrepreneurs, the coherence of entrepreneurial activities that create the pathway, and resources availability in the ecosystem and the entrepreneur's perception and exploitation of the resources. From the orientation/ intentionality to exploitation of opportunities and resources in the ecosystem to develop the pathway trajectories through a series of entrepreneurial activities, they are driven by that entrepreneurial energy. This brings to the next research question- uncovering the determinants of entrepreneurial energy that pervades in the ecosystem. This paper will theorize that the lens of complex adaptive systems can be used to understand the linkages between these forces that operate in the ecosystem across spacetime. Complexity science can illuminate the study of the entrepreneurial ecosystem by providing insights into their emergence. The study of the complex constellation of connections among the ecosystem components. The ecosystem is best treated as a system, and that system theory which is an analytical approach, represents the phenomena as sets of stocks and flows regulated by interactions (Roundy et al., 2018). The first approach assumes that systems are commonly in (or near) equilibrium depict the study under the broad heading of determinism, which negates the need to examine dynamic relationships and nonlinear interactions among the systems' elements and instead focuses on isolating and parameterizing stable, individual components. Although the "simple" systems approach is appropriate for explaining the behaviour of some types of systems, a second approach used by a variety of disciplines, including biology, ecology, chemistry, economics, and management suggests 
that there is a second type of system that does not operate at equilibrium (indeterminism). There is a subset of these non-equilibrium systems - complex adaptive systems (CAS) - that cannot be explained using general systems theory. The study of complex adaptive systems - systems in which macrolevel behaviours both emerge from and influence the micro-level interactions of the system's elements has led to an interdisciplinary branch of scholarship referred to as complexity science. This research aims to provide a framework for analysing complex systems' characteristics, such as nonlinearity, crossscale interactions, and emergence. (Roundy et al., 2018).

The entrepreneur's orientation/intentionality and adaptive tensions need to be understood as the first step towards understanding the emergence of a complex adaptive system and identifying the ecosystem and the forces influencing the entrepreneurs' cognition and behaviours, and the level at which these forces operate. Entrepreneurs are the agents driving the creation of the complex system. It is entrepreneurs' intentionality, "the tendency towards a goal that first appears in the individual's mind as a purpose" (Krueger et al., 2000) that acts as a motivating force in an ecosystem and contributes to ecosystem emergence. Scholars adopting a complexity lens have argued that entrepreneurs create new ventures because of "adaptive tensions"- internal states of tension that are triggered by an external source and motivate a creative response by the entrepreneur (Lichtenstein et al., 2007). As Lichtenstein argued, "in the context of a nascent entrepreneur, adaptive tension is created through a perceived opportunity or by a personal aspiration to start a business." Adaptive tensions result from "energy differentials," which occur 
when there are discernible and recognizable differences between the resources within entrepreneurs within the space of the ecosystem under their control, and new pools of resources that they desire to access in the pursuit of opportunities. Adaptive tensions are critical to emergence because they are tied to entrepreneurial orientation/intentions. When entrepreneurs identify, create, and respond to market opportunities, they exhibit intentionality in formulating implicit and explicit means and action plans to drive to their ends. The differential between the orientation/intentions of entrepreneurs and the opportunities and risks assessed on which they seek to capitalize generates pressures to act and the action is premised on the level of entrepreneurial energy spurring the entrepreneurs to act in certain direction.

Complexity science has developed to analyse systems in which the interactions between component elements in the ecosystem result in the emergence of new and unpredictable patterns, behaviours and structures (Anderson et al., 2012). In such systems, the patterns of action produced at one level both emerge from and are influenced by processes operating at different levels and by the behaviours of the overall system, a characteristic referred to as complexity. Systems that exhibit complexity and are adaptive with the capacities to change based on contextual conditions are referred to as complex adaptive systems. In such systems, the individual components are constantly interacting and reacting to one another, including the environment across levels, modifying the system and its response to disturbances and allowing it to adapt to changes. (See Diagram 7). 


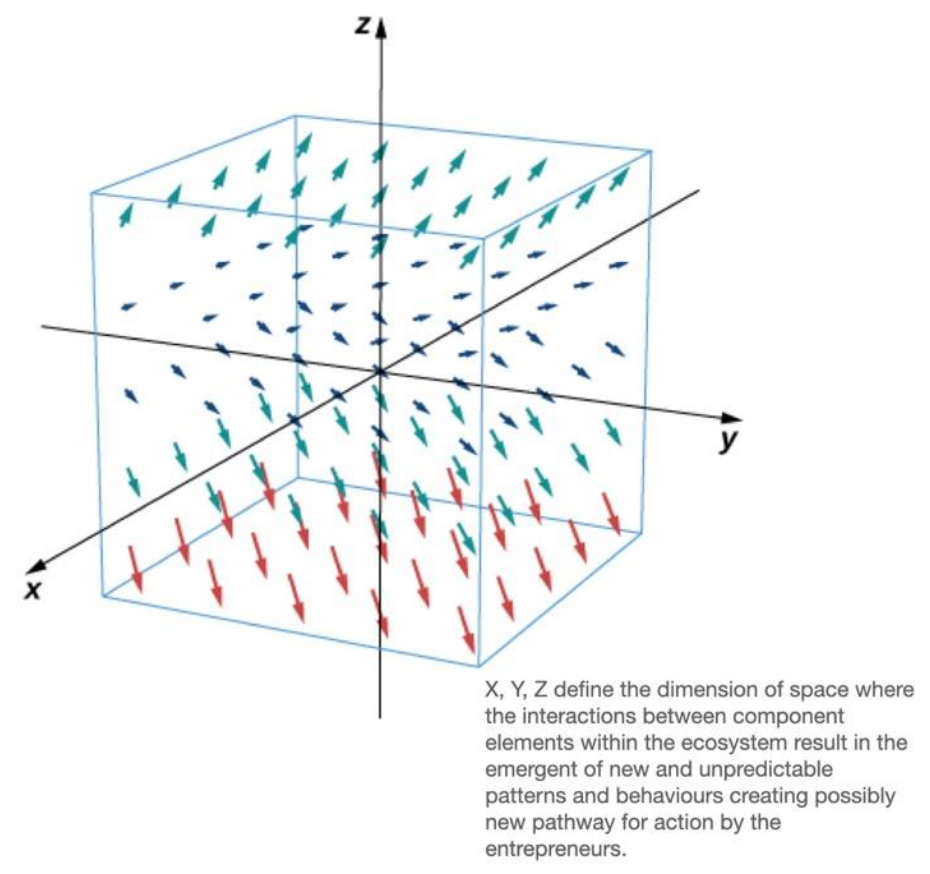

Diagram 7. Possibility space of entrepreneur (source: author's elaboration)

At the core of both complexity science and entrepreneurship study is a focus on the concept of emergence, "the creation of new 'order' (Lichtenstein et al., 2007). Emergence is central to entrepreneurship research, which has emphasized "the coming-into-being of new venture pathways. Through interactions with one another (risks, opportunities, other economic actors' actions and counter-actions), these interactivities produce continuous modifications to the system, shaping how the system responds to endogenous and exogenous disturbances and allows it to adapt to changing and novel conditions. 
These dynamics can lead to path variable developments and trajectories because of historical experiences and existing environmental munificence and conditions.

\section{Opportunities and Risks Context}

Of particular interest are questions about the sources of entrepreneurial opportunities. Are entrepreneurial opportunities a result of discovery or one of creation?

To address these questions, (Shane, 2012) distinguishes and defines opportunities to account for both entrepreneurial failures and successes. To advance the notion of entrepreneurial energy emerging at the nexus of the entrepreneurs who are the human agents and opportunities, this paper will explore what does this energy influences and is the impact of the discovery process and to investigate it as a beneficial force that regulates entrepreneurs' actions in the different possible developmental trajectories in entrepreneurship. Opportunities, according to (Sarason et al., 2006b), are objectively presented, so perceptive entrepreneurs can explore and exploit these opportunities by capturing or recombine resources in a way that allows the pursuit of that opportunity". Building on (Davidson, 2001) "tripod" consisting of interactions among objective, subjective, and intersubjective, it conceptualizes entrepreneurial opportunities as being both "made" and "found" in and through such interactions. Between the human agency (entrepreneur) and the artefact 
(opportunity) and as a result of the relational processes, it is therefore suggested that entrepreneurial energy spurs the entrepreneur to action in the acquisition of that opportunity.

Opportunities can be looked from "discovery" and "creation" perspectives (Alvarez \& Barney, 2007). From a discovery perspective, opportunities are exogenously presented in the entrepreneurial ecological space (see Diagram 3), which alert entrepreneurs can seize (Kirzner, 1997). As seen in the diagram, opportunities abound where the entrepreneurs can explore and exploit. In contrast, from a creation perspective, opportunities are endogenously generated through processes such as creative imagination (Lachmann, 1986) and effectuation (Sarasvathy et al., 2001). There is a wellspring of creative entrepreneurial energy in search of entrepreneurial opportunities.

Context matters within the entrepreneurial ecosystem's space as it provides the basis for the generative forces for action to operate, which, in turn, produces new opportunities - that is, the specific manifestation of an entrepreneurial pathway (Alvarez \& Barney, 2013). As the context unfolds, risks and opportunities are transformed in dynamic ways. Human agents/ entrepreneurs are a part of an ecology of interactions within the space in the ecosystem that forms the basis for entrepreneurial pathway developments. The creative imagination of a future that has yet to emerge (Brown, et al., 2000) and sensemaking of what has transpired (Weick \& Karl E, 1995). Seen from a constructivist position, opportunity spaces emerge as the human agents (entrepreneurs), environmental resources, risks and opportunities become entangled 
(and disentangled), thereby dynamically enabling and constraining the entrepreneurs' orientation/intentionality and possibilities (Garud et al., 2010). A consideration of relationality reinforces the fact that opportunities emerge through recombination of relations and resources. Many scholars have established this proposition - in economics (Schumpeter, 1942), who cited "recombination" to create, psychology (Koestler, 1976) who introduced the notion of "bi-sociation", sociology (Hargadon, 2003) who established the importance of "brokers", (Bessant, \& Trifilova, 2017) who advocated "recombinant innovation" and (Lévi-Strauss, 1966) who explored processes such as "bricolage". This innovative recombination suggests that any act of creation from existing elements within the ecosystem is simultaneously an act of discovery, and vice versa and has very much to do with the awareness and alertness of such elements to be able to recompose and reconstitute the whole for innovative creation.

The creative imagination of new ideas from existing ideas or effectuating new pathway necessitate a certain level of positive energy to sustain the momentum of creation. Rarely new ideas or concepts evolve full blown and are totally ready for use, unless it's a hole-in-one eureka moment, as it requires times and expenditure of efforts to shape the idea to fruition and the process is almost never linear. There are false starts and dead ends, ups and downs and "backing and forthing" as the entrepreneurial pathway unfolds (Garud \& Gehman, 2012). While the false starts, dead ends, going into the valley of the curve and "backing and forthing" can be distracting, disconcerting and mostly discouraging but the entrepreneurial energy will hold up to 
spur the entrepreneurs to persist and persevere. Such nonlinear dynamics strengthen the verve and nerve of the entrepreneurs and cultivate within them the temporal orientation that at any given space-time moment, they can assess and look forward and backwards in time to generate "option value" from their construction and improve on them. Past, present and future are intertwined, and entrepreneurs must be able to forge new recombinants from past failures or dead ends and creatively imagine a future, which demands creative energy to push them into the future. This force that causes the movement and continuous motion for discovery and creation is the entrepreneurial energy at work and this paper will explore this energy in action. The individual-opportunity nexus integrates objective and subjective aspects of entrepreneurship (Eckhardt \& Shane, 2013), and this study will feature how the energy works within the nexus.

Structuration theory is another useful lens to view the entrepreneurial process in this paper. Entrepreneurship is presented as the nexus of opportunity and agency, whereby opportunities are not singular phenomena but are idiosyncratic to the individual. Entrepreneurial ventures are the basis and outcome of the entrepreneurs' actions. The traditional view of entrepreneurship is that entrepreneurs fill market gaps (Sarason et al., 2006b). A structuration view proposes that the entrepreneur and social systems co-evolve by theorizing the entrepreneurial process which is a dynamic interaction where the sources of opportunities are acted on by the entrepreneurs, and at the same time, the entrepreneurs are affected by the sources of opportunities. The entrepreneur is a reflexive agent engaging in purposeful action. 
Structuration theory is developed by the sociologist Anthony Giddens, explains how actors are the creators of social systems, yet at the same time are created by them. Giddens (1984) describes the framework as an attempt to provide the conceptual means of analysing the often delicate and subtle interlacing of reflexively organized action and institutional constraint. Structuration theory presents the agent as being simultaneously enabled and constrained by social structuring, which is the context entrepreneurs experience, both sense of emancipation and constriction at the same time. The entrepreneur and opportunity's interactivity is conceptually a duality where one cannot exist independently of the other; therefore, it cannot be understood separate and distinct from each other. Diagram 7 provides an illustrative interaction between the entrepreneur and opportunities in the space. Through the lens of structuration theory, it is an alternative perspective on how entrepreneurs interpret and influence their world through their perception leading to purposeful actions. This motion from perception to action is agitated by energy. Structuration theory suggests that social structures both constrain and enable entrepreneurs (Manning, 2008) in the venturing processes of discovery, evaluation, and exploitation of opportunities. Entrepreneurial opportunities can be depicted as being interdependent with the entrepreneur's actions as it co-evolves with the entrepreneur's actions and attempts to understand opportunities as distinct from the entrepreneur cannot be entirely descriptive as it is perpetually a story in the making. A structuration theory representation of the process can enlighten and empower entrepreneurs. Opportunities do 
not exist a priori waiting to be discovered, but become manifested to the entrepreneur and to others as they are conceptualized and developed by the actor as part of the venturing process (Sarason et al., 2006b). The creative act in the discovery involves the evaluation and resource acquisition of a new conceptualization with a myriad of combinatorial possibilities and permutations developed as part of the venturing process of exploration. The idiosyncratic, path-independent nature of venture creation where many finalities through multiple means and pathways can be taken show how entrepreneurs and the opportunities in their interactions produce different outcome basing on interpretation of opportunities and the context of the environment then. The sources of opportunity and the structuring processes are constructed and reconstructed iteratively in the entrepreneur's ongoing process. Structuration theory contributes to this paper's goal of presenting it as a framework so that what moves and motivates an entrepreneur to specific action is the carry-on effect of the energy existing in the system.

\section{Conclusion}

This thesis starts with the defining entrepreneurship pivoting on subjective ontology and subjective epistemology and describing further on the disequilibrium and complexity in entrepreneurship space moving from a discussion of determinism study to indeterminism in entrepreneurship. Rather than searching for entrepreneurs and/or opportunities as an individual phenomenon, the true key to understanding entrepreneurship is to examine the nexus 
of the two (Shane \& Venkataraman, 2000) which is the space in which the two interact which is covered in the section "Space Context". However, the nature of this nexus can be comprehended through the theoretical lens of complexity science and structuration theory that accounts for both individual and structural elements and to provide a comprehensive conceptualization of the nature of the nexus/ space. These theoretic lenses provide a conceptual foundation useful in the study of entrepreneurship in this thesis and to discuss how entrepreneurial energy agitates the entrepreneurs along time to move them to purposeful action. Studying the entrepreneur and the entrepreneurial opportunity as a duality in a dynamic way provides contextual richness to the entrepreneurial theory and provides insights into the phenomenon's nature. The research methodologies highlight how entrepreneurs respond to entrepreneurial energy and how it affects cognitive, affective, and effective actions. Through these theoretic lenses and the effect of entrepreneurial energy this paper hopes to effectively and elegantly help interpret how entrepreneurs influence their world to accomplish their purposes through human action as covered under the section "Human Actions". The theories employed in this paper suggest how social systems both constrain and enable entrepreneurs in the processes of discovery, evaluation, and exploitation of opportunities and the study of opportunities is covered under the section of "Opportunities and Risks Context". In these pursuits under the different sections and headings, the focus is on the recursive nature of entrepreneur-opportunity relationships through time and space with human actions, as longitudinal perspectives that 
reveal the complex dynamics of mutual interdependence between agent, structure, space, time and energy.

\section{References}

1. Alvarez, S. A., \& Barney, J. B. (2007). Discovery and creation: alternative theories of entrepreneurial action. Strategic Entrepreneurship Journal, 1(1-2), 11-26.

2. Alvarez, S. A., \& Barney, J. B. (2013). Epistemology, opportunities, and entrepreneurship: Comments on Venkataraman et al. (2012) and Shane (2012). In Academy of Management Review (Vol. 38, Issue 1, pp. 154-157).

3. Anderson, A. R., Dodd, S. D., \& Jack, S. L. (2012). Entrepreneurship as connecting: some implications for theorising and practice. Management Decision 50(5), 1-12.

4. Bessant, J., \& Trifilova, A. (2017). Developing absorptive capacity for recombinant innovation. Business Process Management Journal, 23(6), 1094-1107.

5. Brown, N., Rappert, B., \& Webster, A. (2000). Contested Futures: A Sociology of Prospective. Techno-Science. Ashgate, Aldershot.

6. Cantillon, R, . (1931). Essai sur la nature du commerce en g'en'eral. H. Higgs.

7. Chiles, T. H., Bluedorn, A. C., \& Gupta, V. K. (2007). Beyond creative destruction and entrepreneurial discovery: A radical Austrian approach to entrepreneurship. Organization Studies, 28(4), 467-493.

8. Cornelissen, J. P., \& Clarke, J. (2010). Imagining and rationalizing opportunities: Inductive reasoning and the creation and justification of new ventures. In Academy of Management Review, 35(4), 539.

9. Cvitanovi, P. (2000). Chaotic Field Theory: A Sketch.

10. Davidson, D. (2001). Subjective, Intersubjective, Objective. Philosophical Essays: Volume 3. Clarendon Press.

11. Davidsson, P. (2015). Entrepreneurial opportunities and the entrepreneurship nexus: A re-conceptualization. Journal of Business Venturing, 30(5), 674-695.

12. Eckhardt, J. T., \& Shane, S. A. (2013). Response to the commentaries: The individual-opportunity (IO) nexus integrates objective and subjective aspects of entrepreneurship. Academy of Management Review, 38(1), 160-163.

13. Espinas, A. V. (1897). Les origines de la technologie. Paris. 
14. Garud, R., \& Gehman, J. (2012). Metatheoretical perspectives on sustainability journeys: Evolutionary, relational and durational. Research Policy, 41(6), 980-995.

15. Garud, R., Kumaraswamy, A., \& Karnøe, P. (2010). Path dependence or path creation? Journal of Management Studies, 47(4), 760-774.

16. Giddens, A. (1984). The Constitution of Society: Outline of the Theory of Structuration. In Cambridge: Polity Press.

17. Goldstein, J. (2013). Emergence: A construct amid a thicket of conceptual snares. In Complexity and Organization: Readings and Conversations. https://doi.org/10.4324/9781315887784

18. Hargadon, A. B. (2003). How Breakthroughs Happen: The Surprising Truth about How Companies Innovate. Boston: Harvard Business School Press.

19. Johnson, P., \& Duberley, J. (2000). Understanding Management Research. https://doi.org/10.4135/9780857020185.n1

20. Keynes, J. M. (1936). The General Theory of Interest, Employment and Money. London: Macmillan.

21. Kirzner, I. (1997). Entrepreneurial discovery and the competitive market process. An Austrian Approach. Journal of Economic Literature, 35, 60-85.

22. Knight, F. (1921). Risk, uncertainty and profit. New York: Augustus Kelley.

23. Koestler, A. (1976). The act of creation. London: Hutchinson.

24. Krueger, N. F., Reilly, M. D., \& Carsrud, A. L. (2000). Competing Models of Entrepreneurial Intentions. Journal of Business Venturing, 15, 1-12.

25. Lachmann, L. M. (1986). The market as an economic process. Wiley-Blackwell.

26. Leong, D. (2020). Entrepreneurial Energy and Opportunities Existing in Space. Journal of Entrepreneurship, Business and Economics, 8(2), 196-218.

27. Lévi-Strauss, C. (1966). The savage mind. . Chicago, IL: University of Chicago Press.

28. Lichtenstein, B. B. (2007). Moving Far from Far-From-Equilibrium: Opportunity Tension as the Driver of Emergence. Organization Science Winter Conference. http://scholarworks.umb.edu/management_wphttp://scholarworks.umb.edu/management_wp/13

29. Lichtenstein, B. B., Carter, N. M., Dooley, K. J., \& Gartner, W. B. (2007). Complexity dynamics of nascent entrepreneurship. Journal of Business Venturing, 22(2), 236-261.

30. Manning, S. (2008). Embedding projects in multiple contexts - a structuration perspective. International Journal of Project Management, 26(1), 30-37. 
Leong, D. 2021. Entrepreneurial Energy in a Far-From-Equilibrium Opportunity Driving Entrepreneurial Actions

31. Mckelvey, B. (2002). Good" Science From Postmodernist Ontology: Organization Science, March 1998.

32. McKelvey, B. (2004). Toward a 0 th Law of Thermodynamics: Order-Creation Complexity Dynamics from Physics and Biology to Bioeconomics. Journal of Bioeconomics, 6(1), 65-96.

33. Mises, L. Von. (1949). Human action: A treatise on economics (4th revised ed.). In San Francisco: Fox \& Wilkes.

34. Plowman, D. A., Baker, L. T., Beck, T. E., Kulkarni, M., Solansky, S. T., \& Travis, D. V. (2007). Radical change accidentally: The emergence and amplification of small change. Academy of Management Journal, 50(3), 515-543.

35. Prigogine, I., \& Lefever, R. (1968). Symmetry breaking instabilities in dissipative systems. II. The Journal of Chemical Physics, 48(4), 1695-1700.

36. Ramoglou, S. (2013). Who is a "non-entrepreneur"?: Taking the "others" of entrepreneurship seriously. International Small Business Journal, 31(4), 432-453.

37. Randerson, K., Degeorge, J. M., \& Fayolle, A. (2016). Entrepreneurial opportunities: How do cognitive styles and logics of action fit in? International Journal of Entrepreneurship and Small Business, 27(1), 19-39.

38. Roundy, P. T., Bradshaw, M., \& Brockman, B. K. (2018). The emergence of entrepreneurial ecosystems: A complex adaptive systems approach. Journal of Business Research, 86, 1-10.

39. Sarason, Y., Dean, T., \& Dillard, J. (2006a). Entrepreneurship as the Nexus of Individual and Opportunity: A Structuration View DLU-JOS CALL FOR PAPERS: Special Issue on Entrepreneurship and Innovation, and Social Entrepreneurship View project. Journal of Business Venturing. https://doi.org/10.1016/j.jbusvent.2005.02.007

40. Sarason, Y., Dean, T., \& Dillard, J. F. (2006b). Entrepreneurship as the nexus of individual and opportunity: A structuration view. Journal of Business Venturing, 21(3), 286-305.

41. Sarason, Y., Dillard, J. F., \& Dean, T. (2010). How can we know the dancer from the dance?. Reply to "Entrepreneurship as the structuration of individual and opportunity: A response using a critical realist perspective". (Mole and Mole, 2008). In Journal of Business Venturing, 25(2), 238-243.

42. Sarasvathy, S., Kotha, S., \& Hall, M. (2001). Effectuation in The Management of Knightian Uncertainty: Evidence from the Realnetworks Case.

43. Schumpeter, J. A. (1934). The theory of economic development. Cambridge, MA: Harvard University Press. 
44. Schumpeter, J. A. (1942). Creative Destruction" From Capitalism, Socialism and Democracy.

45. Shane, S. (2012). Reflections on the 2010 AMR decade award: Delivering on the promise of entrepreneurship as a field of research. Academy of Management Review, 37(1), 10-20.

46. Shane, S., \& Venkataraman, S. (2000). The Promise of Entrepreneurship as a Field of Research. In Source: The Academy of Management Review, 25(1), 1-12.

47. Soros, G. (2013). Fallibility, reflexivity, and the human uncertainty principle. Journal of Economic Methodology, 20(4), 309-329.

48. Valliere, D. (2013). Towards a schematic theory of entrepreneurial alertness. Journal of Business Venturing, 28(3), 430-442.

49. Venkataraman, S., Sarasvathy, S. D., Dew, N., \& Forster, W. R. (2012). Reflections on the 2010 AMR decade award: Whither the promise? moving forward with entrepreneurship as a science of the artificial. Academy of Management Review, 37(1), 21-33.

50. Walras, L. (1874). Elements d economie politique pure. L. Corbaz, Lausanne.

51. Weick, ., \& Karl E, . (1995). Sensemaking in organizations. . Thousand Oaks, CA: SAGE.

52. Weick, ., Karl E, ., Sutcliffe, K. M, ., \& Obstfeld, D, . (2005). Organizing and the Process of Sensemaking. . Organization Science, 16(4), 409-421.

David Leong, $\mathrm{PhD}$ started his entrepreneurial ventures early, soon after he graduated from the National University of Singapore in 1994 with a Bachelor of Business Administration degree. He has founded various ventures from corporate finance, business consultancy, design consultancy, human resources (HR), publication and technology. David was awarded his PhD from Charisma University in 2020 and is pursuing his Doctor of Business Administration with the University of Canberra for a double doctorate. His research is in entrepreneurship, and he is venturing to define "entrepreneurial energy" as the energy field spurring entrepreneurial actions in the light of complex science and quantum science. His other research area is in the Chinese Yijing, and he draws the relatedness of Yijing with modern science in particular quantum physics. http://straitstrades.com/david/ 